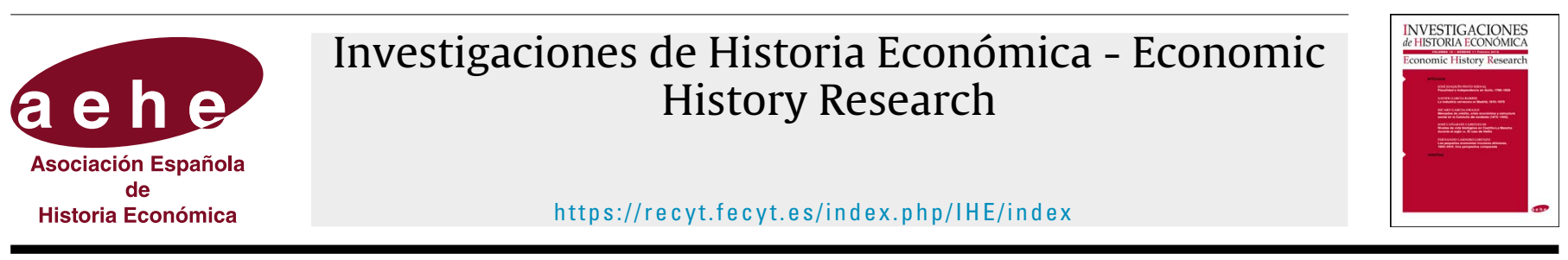

Reseña

\section{Emanuele Felice. Historia Económica de la Felicidad. Una nueva visión de la historia del mundo. Barcelona, Edito- rial Crítica, 2020, 352 pp. ISBN: 978-8491991885.}

Emanuelle Felice es un economista con una dilatada producción científica orientada al análisis del crecimiento económico, la desigualdad regional y la relación entre las instituciones y el desarrollo siempre bajo un enfoque de largo plazo. Ahora utiliza su experiencia para ofrecernos un texto divulgativo que busca dar respuesta a una pregunta: ¿qué relación existe entre crecimiento económico y felicidad? Para ello se embarca en una amplia revisión del conocimiento acumulado a lo largo del tiempo por disciplinas como la economía, la historia, la filosofía y la política. Si bien el título del libro, Historia económica de la felicidad, deja bastante claro lo que se quiere transmitir, el subtítulo no deja sospecha de lo que nos encontraremos: Una nueva visión de la historia del mundo.

De partida, se agradece que Felice acote el alcance del término de felicidad sobre el cual se desarrolla el ensayo: libertad (referida a la autonomía sobre las limitaciones materiales y la capacidad de no interferir en las libertades de otros); las relaciones sociales bajo un enfoque colaborativo antes que utilitario, y la autodeterminación para buscar el "sentido a la vida». Habiendo definido el punto de llegada, los seis capítulos que componen el libro hacen un recorrido por las distintas apreciaciones que la felicidad ha tenido en la historia. Desde la revolución cognitiva y la llegada de los sapiens, pasando por la revolución agrícola, hasta llegar la Revolución Industrial y su influencia en la sociedad del siglo xxı. En mi opinión, ese el principal atractivo: la idea de que la felicidad ha estado presente a lo largo de la historia, en este caso, económica. Si bien se trata de un concepto que ha ido cambiando, Felice logra identificar puntos de quiebra recogidos por varias especialidades del saber para ensamblar una noción de felicidad y su interpretación de largo aliento. Por ejemplo, la afirmación sobre la revolución agrícola como un proceso impuesto por el incremento de la población, que derivó en una pérdida de bienestar que estaba presente en el sistema de caza y recolección, podría convencer o no al lector. No obstante, Felice recurre al enfoque multidisciplinario para tejer los argumentos de cada capítulo, cuyo resultado es una trama con avances y retrocesos en la búsqueda (o no) de la felicidad.

El siguiente mérito que encuentro es haber puesto sobre la mesa el enorme aporte que, desde la Ilustración se hizo al desarrollo de las ciencias. Felice reivindica las ideas de los distintos pensadores de ese período para cimentar el concepto de felicidad que propone. Al punto que, en términos generales, el libro se podría dividir en dos interpretaciones de felicidad, según que incluyan o no la influencia de este movimiento intelectual. Con esto, el libro se apoya en pensamientos ampliamente meditados, con gran recorrido histórico y a los que una parte importante del mundo debe su sistema de organización. Al mismo tiempo, se trata de un reconocimiento para quienes en su momento arrojaron luz para entender fenómenos desconocidos y para reinterpretar los ya conocidos.

Otra influencia que se encontrará en Historia económica de la felicidad será la de Yuval Harari y su libro Sapiens, algo que Felice reconoce en su introducción. Aunque este aspecto está presente en los primeros capítulos, no es menos cierto que, conforme se desarrolla el libro, va forjando su propia identidad. Dejo al lector en libertad para valorar si esto constituye un punto a favor o no de esta obra.

Por otro lado, un elemento que pudo incluirse en el libro es la aportación que desde la cosmovisión indígena del continente americano puede hacerse sobre la vida humana. Así, en la región andina se ha incorporado el sumak kawsay (buen vivir) en Ecuador y suma qamaña (vivir bien) en Bolivia. En ambos casos son planteamientos que están presentes en el ordenamiento jurídico de esos países al menos desde hace una década, pero es un concepto que se viene debatiendo desde 1990. En el núcleo de estas visiones está el construir una vida orientada a cultivar los bienes relacionales antes que los materiales. Habría sido interesante apreciar la interacción de este concepto con el relato presentado.

Finalmente, Historia económica de la felicidad es un libro que te invita a pensar y regresar sobre la historia que tenías preconcebida y a la que no habías reparado en añadir el elemento de la felicidad. Recomendable. Para los iniciados o quienes buscan un primer acercamiento a esta disciplina, se encontrarán con un ejemplo de cómo las distintas especialidades de las ciencias pueden interactuar para que, en este caso, se intente encontrar una explicación sobre cómo ha ido variando la idea de la felicidad. Para los historiadores económicos es una invitación a la reflexión, pero, sobre todo, al debate.

Julio Reyna Pérez Universitat de Barcelona

https://doi.org/10.33231/j.ihe.2020.12.001 